Available online on 15.07.2020 at http://ujpr.org
Universal Journal of Pharmaceutical Research
An International Peer Reviewed Journal
Open access to Pharmaceutical research

\title{
USE OF COLCHICINE TO COUNTERACT THE STRONG HYPERINFLAMMATORY STATE INDUCED BY SARS-COV-2

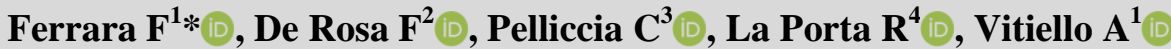 \\ ${ }^{1}$ Usl Umbria 1, Perugia, Italy; ${ }^{2}$ Regione Campania, Naples, Italy. \\ ${ }^{3}$ Usl Umbria 2, Terni, Italy; ${ }^{4}$ Asur Marche, Macerata, Italy.
}

\section{ABSTRACT}

Research in present time has been focusing on finding a specific SARS-CoV-2 vaccine or antiviral, which will probably be the therapeutic goal in the fight against the virus. In the meantime, scientific evidence shows that it is possible to have effective clinical improvements of infected patients in reducing the strong hyperinflammatory state. The SARS-CoV-2 infection is divided into three stages. The most serious phase is the third one where the immune system overdrives and launches an intense attack against itself. This is called "cytokine storm" and leads to tissue damage and often to death. Stopping the cytokine storm early is definitely an effective move; since March several studies have been evaluating how this can be an important pharmacological aspect. Blocking IL-6 or IL-1 inhibitors, for example, is already known to have wide efficacy, but they are not alone in being able to block the cascade of cytokines. This is a clinical pharmacology article and demonstrates how the use of colchicine, monotherapy or in combination in all three phases of SARS-CoV-2, controls inflammation and prevents patient death. Colchicine is safe and effective for treating SARS-CoV-2 patients in preventing inflammation and lung collapse and is certainly useful as an added remedy for other drugs. The advantage is certainly its safety profile much higher than that provided by other drugs, such as corticosteroids and immunosuppressive drugs. Note is the story of hydroxychloroquine: use has been banned due to its high toxicity.

Keywords: Colchicine, coronavirus, cytokine, interleukin, pneumonia, SARS-CoV-2.

Article Info: Received 25 April 2020; Revised 4 June; Accepted 6 July, Available online 15 July 2020

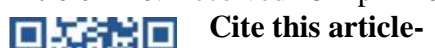

Ferrara F, De Rosa F, Pelliccia C, La Porta R, Vitiello A. Use of colchicine to counteract the strong hyperinflammatory state induced by SARS-CoV-2. Universal Journal of Pharmaceutical Research 2020; 5(3):5356. DOI: https://doi.org/10.22270/ujpr.v5i3.417

Address for Correspondence

Francesco Ferrara, Farmacista Dirigente, Distribuzione Diretta Area Sud, Usl Umbria 1, Perugia, Italy. E-mail: francesco.ferrara@uslumbria1.it

\section{INTRODUCTION}

At the end of 2019, a new coronavirus identified as SARS-CoV-2 was contracted in China and caused thousands of pneumonia resulting in deaths. It quickly spread all over the world. Much has been understood about SARS-CoV-2 and its pathogenesis. SARS-CoV2 infection can be divided into three phases: phase 1 , asymptomatic period that does not require hospitalization; phase 2, slightly symptomatic period with virus detection; phase 3, severe symptomatic phase and strong hyper inflammatory state. Phase 3 is most serious and dangerous because the strong inflammation causes lethal pneumonia due to a large release of cytokines defined as "cytokine storm" $(\mathrm{CS})^{1,2}$.

\section{Phases of SARS-CoV-2 infection}

For each pathological phase, a specific therapeutic treatment can be indicated or avoided. Every single phase must be well identified from patient to patient because the therapeutic approach is different ${ }^{3,4}$.
Phase 1 (or non-serious phase)

At this stage the patient is infected and the immune system tries to counter it. This phase lasts between three and seven days. At this stage, an immune response is required that is suitable for breaking down the virus and avoiding progression in the later stages of the disease. The use of an antiviral to lower the viral load is definitely helpful and would stimulate the immune system to react effectively. Encouraging evidence of efficacy concerns remdesivir, lopinavir/ ritonavir, chloroquine and hydroxychloro- quine. If the virus is defeated at this stage there is an easy clinical recovery $^{5,6}$.

Phase 2 (moderate)

The second stage of infection occurs between the tenth and fourteenth days. The protective immune response has failed and the virus cannot be defeated. The deep respiratory tract is the tissue that is exposed to the greatest risk of pneumonia ${ }^{7,8}$. This is also called the hypoxic phase with urgent hospitalization. Heart and 
clotting problems they are frequent, leading the patient to aggravate his clinical picture. Laboratory tests show a marked increase in pro-inflammatory molecules. Cocombined treatment of antiviral, oxygen and antiinflammatory drugs is the ideal solution to treat these patients, the administration of low molecular weight heparin should always be used to prevent thromboembolic events ${ }^{9,10}$.

Phase 3 (severe)

The third stage leads to the patient's death and is therefore the most serious. The hyperactive inflammatory state called Cytokine Storm (CS) quickly leads the patient to respiratory distress syndrome $(A R D S)^{11,12}$. In this phase the values of the proinflammatory molecules (IL-2, IL-6, GCSF, TNFalpha, D-dimer, ferritin, etc.) are very high with severe respiratory insufficiency and cardiac shock. Immunological therapies (corticosteroids, antiinterleukin 6, such as tocilizumab and sarilumab, IL-1 receptor antagonists such as anakinra or canakinumab, JAK inhibitors, convalescent plasma) are needed in this phase to reduce the inflammatory response triggered by cytokines. The prognosis is obviously very serious ${ }^{13,14}$.

Table 1: Trials on going with colchicine in SARS-Cov-2 patients.(Clinicaltrials.gov).

\begin{tabular}{ccc}
\hline Row & Study Title & Conditions \\
\hline 1 & $\begin{array}{c}\text { Colchicine Coronavirus SARS-CoV2 } \\
\text { Trial (COLCORONA) }\end{array}$ & $\begin{array}{c}\text { Corona Virus Infection } \\
\text { Colchicine in Covid-19 }\end{array}$ \\
\hline 3 & $\begin{array}{c}\text { The GReek Study in the Effects of } \\
\text { Colchicine Efficacy in COVID-19 } \\
\text { Pneumonia }\end{array}$ & $\begin{array}{c}\text { Corona Virus Infections } \\
\text { Pneumonia Viral }\end{array}$ \\
\hline 4 & The ECLA PHRI COLCOVID TRIAL & SARS-Cov-2 infection \\
\hline 5 & $\begin{array}{c}\text { Colchicine Counteracting } \\
\text { Inflammation in COVID-19 } \\
\text { Pneumonia (ColCOVID-19) }\end{array}$ & SARS-Cov-2 \\
\hline 6 & $\begin{array}{c}\text { Treatment with colchicine of patients } \\
\text { affected by Covid-19:A pilot Study" }\end{array}$ & SARS-Cov-2 \\
\hline
\end{tabular}

\section{Colchicine}

Colchicine is a well-known drug and used in various therapies such as family Mediterranean fever (FMF) in which it has the greatest clinical success, in addition to traditional anti-gout $u_{\mathrm{se}}{ }^{15}$. The anti-inflammatory properties of the drug make it suitable for its use in SARS-CoV-2 infection by interfering in the cascade of cytokines at different levels with multiple mechanisms. Binding the tubulin molecule and therefore inhibiting its polymerization as microtubules in neutrophils is the main mechanism of action, thus migration is inhibited. In addition, the formation of adhesion molecules is altered, leading to a strong inhibition of the interaction between white blood cells and endothelial cells. For these reasons, the anti-inflammatory effect has multiple mechanisms of action ${ }^{16}$. The beneficial effects in SARS-CoV-2 are probably due to the inhibition of IL1, IL-6 and IL-18 because colchicine can interfere with the inflammatory protein complex NLRP3 which is primarily responsible for the release of cytokines.

The NLRP3 inflammasome is activated in various ways and has a major role in the development of the cytokinin storm from SARS-CoV-2. Its upstream inhibition can be considered as prevention or treatment of SARS-CoV-2. Many clinical trials are currently underway to investigate the use of colchicine in positive Covid patients, as detailed in Table 1 .

Colchicine (at a dose of $0.5-2 \mathrm{mg} / \mathrm{day}$ ) is the gold standard drug in FMF prophylaxis ${ }^{17}$. Extending the use of colchicine to SARS-Cov2 is closely related to its main indication. FMF is an inherited autoinflammatory disease with febrile episodes (attacks) and severe inflammation. The use of colchicine ( $\max 3 \mathrm{mg} /$ day) is proven to have an efficacy in preventing inflammatory attacks ${ }^{18}$. Based on its safe and known tolerability profile after many years of clinical practice, this drug can be used both as monotherapy and in combination in all three stages of coronavirus infection as shown in Table 2.

Table 2: Hypothetical timing of clinical pharmacological management of the inflammatory state in the SARS-Cov-2 patient.

\begin{tabular}{cccc}
\hline & Phase 1 & Phase 2 & Phase 3 \\
\hline COL & Prophylaxis & Treatment & Treatment \\
HCQ & & Treatment & Treatment \\
TCZ/SAR & & Treatment? & Treatment \\
\hline
\end{tabular}

Colchicine as monotherapy in phase 1 and for complications prevention in phase 2 or 3

The drug used in common doses, according to the existing literature that narrates the effective treatments in FMF, is a good remedy in phase 1 of the positive covid pathology. Practically a low initial dose $(0.5 \mathrm{mg} /$ day) can be used as a preventive method to avoid going to the next stages. This therapy can also be used in combination with antivirals to reduce virus replication pending the immune system's reaction to the infection. At standard doses colchicine, unlike other drugs, has a good tolerability profile and this is very important to combat the first phase where you must avoid administering immunosuppressants or glucocorticoids because they depress the immune system ${ }^{19,20}$.

Colchicine as monotherapy or in combination for phase 2 treatment

This phase is crucial and therapy should be carefully decided based on the patient's clinical condition. Antivirals at this stage could have their use even if therapeutic interactions and adverse effects need to be monitored. Based on clinical analyzes, the variation in doses of colchicine is an appropriate strategy to be put in place: bring the dose of $0.5 \mathrm{mg}$ twice a day if the 
patient is an adult with a body weight greater than 70 $\mathrm{kg}$. Another therapeutic approach is the combination of colchicine always at $0.5 \mathrm{mg}$ with hydroxychloroquine in low doses to avoid toxic effects. Colchicine and hydroxychloroquine have synergistic action on inflammation and in addition there is also the antiviral action of hydroxychloroquine to support it in phase $2^{21}$. (Figure 1) The use of anti IL6 or anti IL1 or glucocorticoids should be considered based on the patient's clinical picture ${ }^{22}$.

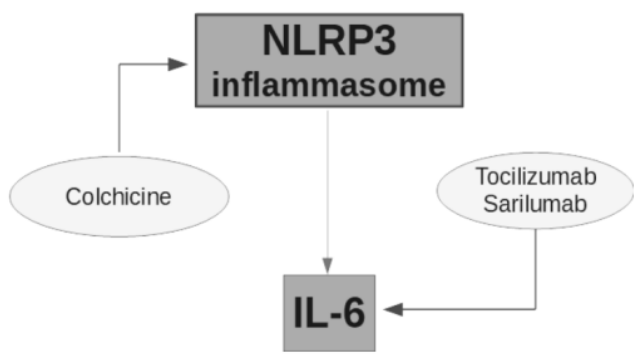

Figure 1: Pharmacological synergism of the association colchicine-chloroquine.

Colchicine in association for phase 3 treatment Slowing down or blocking the uncontrolled inflammatory response is the main objective of this pathological phase in which the release of cytokines occurs. Antiviral treatments are overshadowed and their benefits at this level are quite questionable as the risks of the benefits are highe ${ }^{23} \mathrm{r}$.

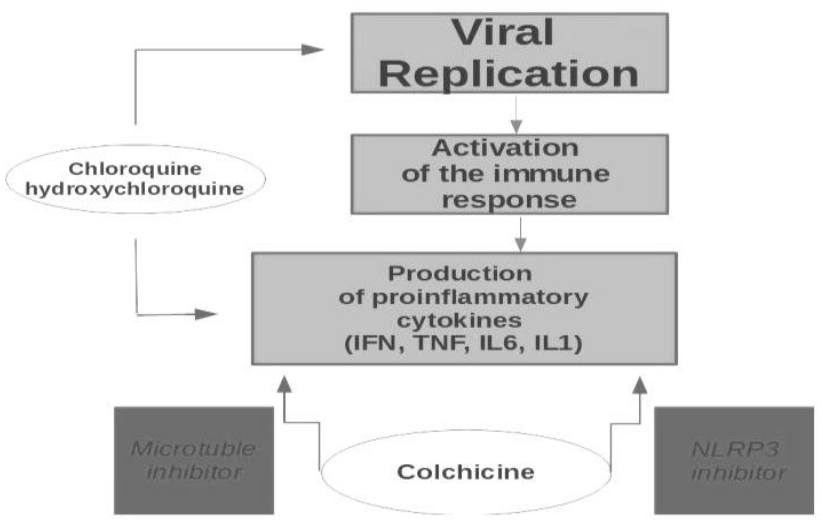

Figure 2: Pharmacological synergism of the association colchicine-inibhitors IL-6.

Anti-inflammatory therapy must be further strengthened to avoid patient death. There are many anti-inflammatory drugs, including non-steroidal antiinflammatory drugs, glucocorticoids, immunemodulators ${ }^{24}$. While the use of glucocorticoids appears to be of little use also in relation to the dose to be used, the use of cytokine inhibitors such as tocilizumab (IL-6 inhibitor) or anakinra (IL-1 receptor antagonist) have shown good efficacy in numerous studies even if precise efficacy doses have not been identified. The expert opinions of the past few months are constantly overlapping $^{25}$. The main concern, of course, is that immunomodulatory drugs increase the risk of infections and therefore there is the risk of delaying the elimination of the virus and risking the appearance of secondary infections. The IL-6 tocilizumab and sarilumab inhibitors have shown good antiinflammatory efficacy and are therefore used in rheumatoid arthritis. In addition, on August 30, 2017, Tocilizumab was approved for cytokine release syndrome in the United States and studies are underway to evaluate its use in FMF, just like colchicine $^{26}$. This we don't think is a coincidence. Colchicine $(0.5 \mathrm{mg}$ once or twice a day), alone or in combination with IL6 inhibitors to control CS, can make significant clinical progress ${ }^{27}$. The advantage of colchicine compared to other drugs is represented by the inflammatory block upstream of all cytokines and not just one and also has a safe safety profile. The combination of colchicine and IL-6 inhibitors can show a synergistic action as shown in Figure $2(15-28)^{28}$.

\section{CONCLUSION}

SARS-CoV-2 infection can be divided into three phases, respectively: asymptomatic or slightly symptomatic incubation period with or without detectable viruses; slightly symptomatic period with the presence of viruses; severely symptomatic respiratory phase with high viral load and generalized hyperinflammatory state characterized by a sudden release of cytokines in the circulation defined as "cytokine storm" (CS). The combination of different drugs, at doses below monotherapy, may be the most effective and tolerable solution to change the patient's inflammatory state, particularly in the second and third phases.

\section{AUTHOR'S CONTRIBUTION}

All authors have worked equally for this work.

\section{ACKNOWLEDGEMENTS}

The authors extend their thanks and appreciation to the Regione Campania to provide necessary facilities for this work.

\section{CONFLICT OF INTEREST}

No conflict of interest associated with this work.

\section{REFERENCES}

1. Ware LB, Matthay MA. The acute respiratory distress syndrome. N Engl J Med 2000; 342:1334-49. https://doi.org/10.1056/NEJM200005043421806

2. Yufang Shi, Ying Wang Changshun Shao, Jianan Huang, Jianhe Gan, Xiaoping Huang, et al. COVID-19 infection: the perspectives on immune responses. Cell Death \& Differentiation 2020.

https://doi.org/10.1038/s41418-020-0530-3

3. Baggiolini M, Walz A, Kunkel SL. Neutrophil-activating peptide-1/ interleukin-8: a novel cytokine that activates neutrophils. J Clin Invest 1989; 84:1045-9.

https://www.jci.org/articles/view/114265

4. Standiford TJ, Rolfe MW, Kunkel SL. Macrophage inflammatory protein-1: expression in interstitial lung disease. J Immunol 1993; 151:2852-63. PMID: 8360496

5. Suter PM, Suter S, Girardin E, Roux-Lombard P, Grau GE, Dayer JM. High bronchoalveolar levels of tumor necrosis factor and its inhibitors, interkeukin-1, interferon, and elastase, in patients with respiratory distress syndrome after trauma, shock, or sepsis. Am Rev Respir Dis 1992; 145:1016-22. https://doi.org/10.1164/ajrccm/145.5.1016 
6. Siler TM, Swierkosz JE, Hyers TM, Fowler AA, Webster RO. Immunoreactive interleukin-1 in bronchoalveolar lavage fluid of high-risk patients and patients with the adult respiratory distress syndrome. Exp Lung Res 1989;15:88194. https://doi.org/10.3109/01902148909069633

7. Goodman RB, Strieter RM, Martin DP. Inflammatory cytokines in patients with persistence of the acute respiratory distress syndrome. Am J Respir Crit Care Med 1996; 154:602-11.

https://doi.org/10.1164/ajrccm.154.3.8810593

8. Park WY, Goodman RB, Steinberg KP. Cytokine balance in the lungs of patients with acute respiratory distress syndrome. Am J Respir Crit Care Med 2001;164:1896-903. https://doi.org/10.1164/ajrccm.164.10.2104013

9. Donnelly SC, Strieter RM, Reid PT. The association between mortality rates and decreased concentrations of interleukin-10 and interleukin-1 receptor antagonist in the lung fluids of patients with the adult respiratory distress syndrome. Ann Intern Med 1996; 125:191-6. https://doi.org/10.7326/0003-4819-125-3-199608010-00005

10. Arend WP, Joslin FG, Thompson RC, Hannum CH. An IL1 inhibitor from human monocytes: production and characterization of biologic properties. J Immunol 1989; 143:1851-8. PMID: 2528582

11. Arend WP. Interleukin-1 receptor antagonist. Adv Immunol 1993; 54:167-227. https://doi.org/10.1016/S0065-2776(08)60535-0

12. Burger D, Chicheportiche R, Giri JG, Dayer JM. The inhibitory activity of human interleukin-1 receptor antagonist is enhanced by type II interleukin-1 soluble receptor and hindered by type I interleukin-1 soluble receptor. J Clin Invest 1995; 96:38-41. https://doi.org/10.1172/JCI118045

13. Conti P, Ronconi G, Caraffa A, Gallenga CE, Ross R, Frydas I, et al. Induction of pro-inflammatory cytokines (IL-1 and IL-6) and lung inflammation by Coronavirus-19 (COVI-19 or SARS-CoV-2): anti-inflammatory strategies. Masters PS, Perlman, S. 2013; 825-858. https://doi.org/10.23812/CONTI-E

14. Vitiello A, Ferrara F, Pelliccia C, Granata G, La Porta R. Cytokine storm and colchicine potential role fighting SARS-CoV-2 pneumonia. Italian J Med 2020; 14(2). https://doi.org/10.4081/itjm.2020.1284

15. Andrea Savarino, Johan R Boelaert, Antonio Cassone, Giancarlo Majori and Roberto Cauda. Effects of chloroquine on viral infections: an old drug against today's diseases? THE LANCET Infect Dis 2003;3.

https://doi.org/10.1016/S1473-3099(03)00806-5

16. Benhamou J, Drew J, Waldman M, Kalchiem-Dekel. The Use of Colchicine in Respiratory Diseases. Curr Resp Med Rev 2013; 9(5): 300-304. https://doi.org/10.2174/1573398X10666140526235154

17. The Association Between Usage of Colchicine and Pneumonia: A Nationwide, Population-Based Cohort Study. Front. Pharmacol 2019. https://doi.org/10.3389/fphar.2019.00908

18. American Society of Health-System Pharmacists. Colchicine Monograph for Professionals. Drugs.com. Retrieved 27 March 2019

19. Schachner, Lawrence A, Hansen, Ronald C. Pediatric Dermatology E-Book. Elsevier Health Sciences. 2011; 177.

20. Hutchison, Stuart J. Pericardial Diseases: Clinical Diagnostic Imaging Atlas with DVD. Elsevier Health Sciences 2009;58.

21. Colchicine for acute gout: updated information about dosing and drug interactions". National Prescribing Service, Australia. Retrieved 14 May 2010.

22. Dalbeth N, Lauterio TJ, Wolfe HR. Mechanism of action of colchicine in the treatment of gout. Clinical Therapeutics. 2014; 36(10):1465-79.

23. Chen LX, Schumacher HR. Gout: an evidence-based review. J Clin Rheumat 2008; 14(5):S55-62. https://doi.org/10.1097/RHU.0b013e3181896921

24. Colcrys (colchicine, USP) tablets $0.6 \mathrm{mg}$. Drug Approval Package". US Food and Drug Administration. Retrieved 19 August 2018

25. Information for Healthcare Professionals: New Safety Information for Colchicine (marketed as Colcrys)". U.S. Food and Drug Administration. Retrieved 19 August 2018.

26. Van Echteld I, Wechalekar MD, Schlesinger N, Buchbinder R, Aletaha D. Colchicine for acute gout. The Cochrane Dat System Rev 2014; 8(8): CD006190. https://doi.org/10.1002/14651858.cd006190.pub2

27. Alabed S, Cabello JB, Irving GJ, Qintar M, Burls A. Colchicine for pericarditis. The Cochrane Dat System Rev 2014; 8(8): CD010652. https://doi.org/10.1002/14651858.CD010652.pub2

28. Portincasa P. Colchicine, Biologic Agents and More for the Treatment of Familial Mediterranean Fever. The Old, the New, and the Rare. Current Med Chem 2016; 23(1): 60-86. https://doi.org/10.2174/0929867323666151117121706 